\title{
Non-SMC Condensin I Complex Subunit D2 Is a Prognostic Factor in Triple-Negative Breast Cancer for the Ability to Promote Cell Cycle and Enhance Invasion
}

\author{
Yajing Zhang, ${ }^{*}$ Fangfang Liu, ${ }^{\dagger \ddagger \S}$ Chengli Zhang, ${ }^{*}+\|$ Meijing Ren, ${ }^{\dagger \ddagger \S}$ Manchao Kuang, ${ }^{*}$ Ting Xiao, ${ }^{*}$ Xuebing Di, ${ }^{*}$ Lin Feng, * \\ Li Fu, ${ }^{\dagger \ddagger \delta}$ and Shujun Cheng*
}

\begin{abstract}
From the State Key Laboratory of Molecular Oncology, * Department of Etiology and Carcinogenesis, National Cancer Center/National Clinical Research Center for Cancer/Cancer Hospital, Chinese Academy of Medical Sciences and Peking Union Medical College, Beijing; the Department of Breast Cancer Pathology and Research Laboratory, ${ }^{\dagger}$ Tianjin Medical University Cancer Institute and Hospital, Tianjin; the Key Laboratory of Breast Cancer Prevention and Therapy, ${ }^{\ddagger}$ Tianjin Medical University, Ministry of Education, Tianjin; State Key Laboratory of Breast Cancer Research, ${ }^{\S}$ Tianjin; and the Department of Oncology," The Affiliated Hospital of Yangzhou University, Yangzhou University, Yangzhou, China
\end{abstract}

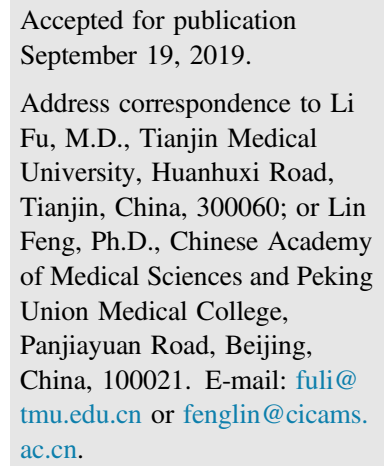

\begin{abstract}
Triple-negative breast cancer (TNBC) is a heterogeneous disease with an unfavorable prognosis and no specific targeted therapies. The role of non-SMC condensin I complex subunit D2 (NCAPD2), a regulatory subunit of the condensin I complex that mainly participates in chromosome condensation and segregation, has not been reported in cancer. We therefore evaluated the prognostic value and biological function of NCAPD2 in TNBC. The expression of NCAPD2 was studied in 179 TNBC tissues by immunohistochemistry, and associations among NCAPD2 expression, clinicopathologic features, and the prognosis information of patients with TNBC were analyzed. The mRNA expression profiles of 99 TNBC tissues were also studied, and cell biological behaviors were detected when NCAPD2 was altered in three TNBC cell lines. NCAPD2 expression was positively associated with lymph node metastasis $\left(P=3.84 \times 10^{-06}\right)$, poor overall survival $(P=0.0033)$, and worse disease-free survival $(P=0.0013)$ of patients with TNBC. Moreover, knockdown of NCAPD2 might cause $\mathrm{G}_{2} / \mathrm{M}$ arrest through the $\mathrm{p} 53$ signaling pathway, which led to proliferation inhibition, polyploid cell production, and cell apoptosis and inhibited the invasiveness of TNBC cells. For the first time, we report the close association between NCAPD2 and cancer and demonstrate that NCAPD2 plays an important role in TNBC progression and acts as an independent poor prognostic factor and a potential therapeutic target for TNBC. (Am J Pathol 2020, 190: 37-47; https://doi.org/10.1016/j.ajpath.2019.09.014)
\end{abstract}

Triple-negative breast cancer (TNBC), which is the most aggressive subtype of breast cancer, accounts for $15 \%$ to $20 \%$ of all patients with breast cancer and is characterized by lack of expression of estrogen receptor (ER) and progesterone receptor (PR) and an absence of amplification of human epidermal growth factor receptor 2 (HER2). ${ }^{1-4}$ TNBCs are a heterogeneous group of tumors, and patients with this subtype are more likely to develop recurrence within the first 5 years; survival after metastatic relapse is shorter for patients with TNBC than patients with other breast cancer subtypes. $^{5-7}$ Because no well-defined molecular targets have been established and no targeted therapies have been approved for TNBC, the only systemic treatment option is cytotoxic chemotherapy, which has limited long-term success rates. $^{8-10}$ Therefore, exploration of the molecular basis of TNBC and developing effective therapeutic strategies, which will eventually improve the survival rate of patients with TNBC, is urgently needed. The segregation of two copies of replicated genomic DNA into each daughter cell is the major

Supported by the Chinese Academy of Medical Sciences Innovation Fund for Medical Sciences grant 2016-I2M-3-005 (S.C.), the National Key Laboratory Independent Innovation Project grant SKL-2017-04 (L.F.), and the Peking Union Medical College Fund of the Funds for the Central Universities grant 3332018072 (L.F.).

Y.Z., F.L., and C.Z. contributed equally to this work.

Disclosures: None declared. 
feature of M phase during the cell cycle. During this period, the relaxed chromatin is converted into condensed chromosomes at the very beginning of mitosis, and the entangled sister chromatids resulting from DNA replication are decatenated. ${ }^{11,12}$ Failure to perform this process accurately can lead to detrimental chromosome segregation defects. ${ }^{13}$ One key factor involved in chromosome condensation and decatenation is a heteropentamer called condensin, which is evolutionarily conserved from bacteria to humans.

Non-SMC condensin I complex subunit D2 (NCAPD2) is a subunit of condensin I that is located on chromosome 12p13.3. Transfection and site-directed mutagenesis studies have confirmed that NCAPD2 is regulated by E2F. ${ }^{14}$ NCAPD2 contains a bipartite nuclear localization signal in its carboxyl terminus, which is necessary for the nuclear localization and chromosome targeting of condensin $\mathrm{I} .{ }^{15} \mathrm{In}$ addition, the HEAT repeat of NCAPD2, which is a bihelical structure arranged in tandem, may play a role in proteinprotein interactions. ${ }^{16,17}$ However, the function of NCAPD2 is not well understood, and previous studies of NCAPD2 have primarily focused on its participation in chromosome condensation and segregation. ${ }^{18-20}$ These studies found that the recruitment of condensin I onto chromosomes depends on the interaction between the chromosome-targeting domain of NCAPD2 and the phosphorylated histone H3. ${ }^{21}$ Several observations have revealed the misalignment of chromosomes on the metaphase plate in the absence of NCAPD2. Moreover, depletion of NCAPD2 affects both the individualization of mitotic chromosomes and the resolution of sister chromatids. ${ }^{13,22}$ Recent research has found that NCAPD2 also interacts with rootletin, which functions in centrosome cohesion and restrains DNA damage-induced centriole splitting. ${ }^{23,24}$ However, as a pivotal participant in the cell cycle, the role of NCAPD2 in cancer has not yet been reported.

In this study, the protein expression level of NCAPD2 was evaluated in 179 primary TNBC samples by immunohistochemistry, and the association among the protein expression, the clinicopathologic features, and the prognosis of these patients was determined. Moreover, mRNA expression profiles of TNBC tissues and NCAPD2 lowexpression TNBC cell models were used to investigate the role of NCAPD2 in TNBC.

\section{Materials and Methods}

\section{Patients and Specimens}

All tissue samples were obtained from 179 female patients who were diagnosed with primary breast cancer and underwent surgery at the Department of Pathology, Tianjin Medical University Cancer Hospital (Tianjin, China) between 2003 and 2006. No patients received chemotherapy or radiotherapy before surgery. Surgically resected tissue samples were fixed in $10 \%$ formaldehyde and then embedded in paraffin for 4- $\mu \mathrm{m}$ histologic sectioning. The histopathologic examination was performed by two independent and experienced pathologists (L.Fu and F.L., who work in the Department of Breast Cancer Pathology and Research Laboratory, Tianjin Medical University Cancer Institute and Hospital, Tianjin, China, and have been engaged in pathologic diagnosis for the last 5 years) who were blinded to the groups in this study. All samples were identified as TNBC by ER, PR, and HER2 staining. The study was reviewed and approved by the Institutional Ethics Committee of Tianjin Medical University Cancer Institute and Hospital, and all patients provided written informed consent. All methods were performed in accordance with the approved guidelines.

\section{Immunohistochemistry and Scoring}

After routine deparaffinization in xylene and rehydration in a graded ethanol of decreasing concentrations, the tissue sections were incubated in $3 \% \mathrm{H}_{2} \mathrm{O}_{2}$ for 10 minutes to block endogenous peroxidase activity. Then the sections were subjected to antigen retrieval by heating in citrate buffer $\mathrm{pH}$ 6.0 at $121^{\circ} \mathrm{C}$ for 150 seconds. After cooling to room temperature, the sections were treated with $5 \%$ normal goat serum to block nonspecific binding and incubated with a mouse monoclonal antibody against NCAPD2 at a 1:100 dilution (catalog number ab56885; Abcam, Cambridge, UK) overnight at $4^{\circ} \mathrm{C}$. Then a biotin-conjugated secondary antibody was applied, and NCAPD2 expression was detected using a streptavidin-peroxidase complex (catalog number SP-9000; Zhongshan Golden Bridge Biotechnology Company, Zhongshan, China). The chromogenic reaction was performed using a commercial diaminobenzidine kit (catalog number ZLI-9550; Zhongshan Golden Bridge Biotechnology Company). Finally, the sections were counterstained in hematoxylin.

The immunohistochemistry-stained sections were analyzed and scored independently by two experienced pathologists (L.Fu and F.L.) who were blinded to the patients' clinicopathologic data. The staining intensity was scored as $0,1,2$, or 3 based on color (no color, ecru, brown, and puce, respectively), and the percentage of positively stained tumor cells was determined, with a staining percentage $\geq 1 \%$ considered positive. The staining intensity scores and the percentage of the positive tumor cells were used to calculate $\mathrm{H}$-scores with the following formula:

$\mathrm{H}$-score $=\Sigma$ (percentage of positively stained tumor cells) $\times$ (staining intensity)

$\mathrm{H}$-scores were then used to categorize the samples into four groups as follows: negative $(-)$, score 0 ; mild $(+)$, score of $>0$ to 1 ; moderate $(++)$, score of $>1$ to 2 ; and marked $(+++)$, score of $>2$ to 3 .

\section{Cell Culture and siRNA Knockdown}

The human TNBC cell lines MDA-MB-231, MDA-MB453, and MDA-MB-468 were obtained from the National Infrastructure of Cell Line Resource (Beijing, China). MDA-MB-231 and MDA-MB-453 cells were maintained in 
RPMI 1640 medium (catalog number 21875109; Gibco, Waltham, MA) supplemented with $10 \%$ fetal bovine serum (DMEM; catalog number 12484-028; Gibco). MDA-MB468 cells were maintained in Dulbecco's modified Eagle's medium (catalog number 11966025; Gibco) supplemented with $10 \%$ fetal bovine serum and $2 \mathrm{mmol} / \mathrm{mL}$ of L-glutamine. All the cell lines were cultured in a humidified incubator at $37^{\circ} \mathrm{C}$ with $5 \% \mathrm{CO}_{2}$.

For the knockdown experiments, cells were transfected with siRNA targeting NCAPD2 (siNCAPD2; catalog number HSS115010; Invitrogen, Carlsbad, CA) or nontargeting control (NC; catalog number 12935100; Invitrogen) using the Lipofectamine RNAiMAX transfection reagent (catalog number 13778150; Invitrogen) according to the manufacturer's instructions.

\section{RNA Isolation and Real-Time RT-PCR}

Total RNA was extracted using TRIzol reagent (catalog number 15596018; Thermo Fisher Scientific, Waltham, MA) and reverse transcribed using a SuperScript II reverse transcription kit according to the manufacturer's protocol (catalog number 18064014; Thermo Fisher Scientific). Then real-time RT-PCR was conducted as described in our previous report. ${ }^{25}$ Melting curves were generated, and the relative mRNA expression level of the target gene was normalized to that of $18 \mathrm{~S}$ ribosomal RNA. All data are presented as the means of three replicates. The primers used for the amplifications are as follows: NCAPD2 forward, $5^{\prime}$ TGGAGGGGTGAATCAGTATGT-3'; NCAPD2 reverse, 5'-GCGGGATACCACTTTTATCAGG-3'; 18S forward, 5'CTGAGAAACGGCTACCACATCC-3'; $18 \mathrm{~S}$ reverse, 5'GCACCAGACTTGCCCTCCA-3'.

\section{CCK-8 Assay}

The proliferation abilities of three TNBC cell lines were measured using the Cell Counting Kit 8 (CCK-8) assay (catalog number CK04; Dojindo, Kumamoto, Japan). Briefly, cells were seeded in 96-well plates at a density of 2000 (MDA-MB-231 and MDA-MB-453) or 4000 (MDA-MB-468) cells per well. After adhesion for 24 hours, the cells were transfected with siNCAPD2 or NC. After incubation for 0 to 120 hours at an interval of 24 hours, the cells were stained with $10 \mu \mathrm{L}$ of CCK- 8 solution in $90 \mu \mathrm{L}$ of culture medium for 2.5 hours at $37^{\circ} \mathrm{C}$ at each time point. Cell proliferation was measured as the absorbance at $450 \mathrm{~nm}$ using a microplate reader (BioTek, Winooski, VT).

\section{In Vitro Invasion Assay}

Corning BioCoat Matrigel Invasion Chambers (24 wells, $8.0-\mu \mathrm{m}$ pore size, Corning, Corning, NY) were used for Transwell invasion assays according to the manufacturer's instructions. Briefly, after 48 hours of transfection, $1 \times 10^{5}$ cells suspended in $500 \mu \mathrm{L}$ of serum-free medium were seeded into the upper chambers, whereas $750 \mu \mathrm{L}$ of complete medium with $10 \%$ fetal bovine serum was injected into the lower chambers as a chemoattractant. After incubation for 24 hours, the cells that had invaded through the membrane were fixed in cold methanol followed by staining with $0.1 \%$ crystal violet, and then cells were counted in at least five fields under a light microscope.

\section{Western Blotting}

Cells were harvested and total protein was extracted using radioimmunoprecipitation assay lysis buffer (catalog number C1053; Applygen, Beijing, China) supplemented with protease inhibitor cocktail (catalog number 78410; Thermo Fisher Scientific). The Pierce BCA Protein Assay Kit was used to quantify the protein concentration (catalog number 23225; Thermo Fisher Scientific). Subsequently, equal amounts of the proteins were separated by SDS-PAGE and transferred onto a $0.25-\mu \mathrm{m}$ polyvinylidene difluoride membrane (catalog number IPFL00010; Millipore, Burlington, MA) via a wet trans-blot system (BioRad, Hercules, $\mathrm{CA})$. The membranes were then blocked and incubated with an antibody against NCAPD2 (catalog number ab56885; Abcam, Cambridge, UK) overnight at $4^{\circ} \mathrm{C}$, followed by incubation with a horseradish peroxidase-conjugated secondary antibody (catalog number ZDR-5307; Zhongshan Golden Bridge Biotechnology Company) and analyzed using an enhanced chemiluminescence detection kit (catalog number P1050; Applygen). Finally, images were obtained with an ImageQuant LAS 4000 mini system (GE Healthcare, Chicago, IL). $\beta$-actin (catalog number sc-58673; Santa Cruz Biotechnology, Santa Cruz, CA) was used as an internal control.

\section{Cell Cycle Assay}

The effect of NCAPD2 on cell cycle distribution was determined by flow cytometry. Briefly, after transfection with siNCAPD2 or NC for 96 hours, cells were harvested, fixed in 70\% ice-cold ethanol, and incubated overnight at $-20^{\circ} \mathrm{C}$. Cells were washed with phosphate-buffered saline and resuspended in $500 \mu \mathrm{L}$ of propidium iodide (PI)/ RNase Staining Buffer (catalog number 550825; BD, Franklin Lakes, NJ). After incubation for 15 minutes in the dark at room temperature, cells were analyzed by flow cytometry using a LSRII flow cytometer (BD). Each experiment was performed at least three times. The fractions of cells in $G_{0} / G_{1}, S$, and $G_{2} / M$ phases and the ratio of polyploid cells were analyzed using ModFit LT software version $3.2(\mathrm{BD})$.

\section{Cell Apoptosis Assay}

Cell apoptosis was detected using the fluorescein isothiocyanate (FITC) Annexin V Apoptosis Detection Kit I 
(catalog number 556547; BD) according to the supplier's protocols. Ninety-six hours after transfection, cells were collected, centrifuged, and resuspended in $500 \mu \mathrm{L}$ of $1 \times$ binding buffer. Then $5 \mu \mathrm{L}$ of Annexin V-FITC and 10 $\mu \mathrm{L}$ of PI were added to each tube. The tubes were incubated in the dark at room temperature for 15 minutes. Cell apoptosis assays were performed immediately on an LSRII flow cytometer (BD).

\section{Analysis of the Public mRNA Expression Data Set}

Normalized mRNA expression data of The Cancer Genome Atlas (TCGA), including 99 TNBC samples and six normal breast tissues from patients with TNBC, were obtained from the cBioPortal for Cancer Genomics database (http://www.cbioportal.org, last accessed April 28, 2019). Pearson's product-moment correlation test was performed to identify genes that were significantly correlated with NCAPD2 $(P<0.001$ and $\mid$ cor $\mid>0.3)$, and DAVID version 6.8 and $\mathrm{R}$ package clusterProfiler was applied to analyze the Gene Ontology (GO) enrichment of gene functions and KEGG pathways (https://david.ncifcrf. gov, last accessed April 28, 2019).

\section{Statistical Analysis}

All results are the means of at least three independent experiments with separately treated and transfected cells. Data are expressed as the means \pm SEM. Statistical analyses were performed using SPSS software version 17.0 (SPSS, Chicago, IL). The correlations between NCAPD2 expression and the clinicopathologic parameters were evaluated using the $\chi^{2}$ test. Survival curves were obtained by the Kaplan-Meier method, and the differences in survival were analyzed by the log-rank test. Multivariate analyses were conducted using a Cox proportional hazards model. Differences were considered statistically significant at $P<0.05$.

\section{Results}

\section{NCAPD2 Is an Independent Prognostic Predictor for TNBC Patients}

In TNBC tissues, the staining pattern of NCAPD2 was intense and clear in the cytoplasm. In general, the rates of negative, mild, moderate, and marked expression were $25.69 \%(n=46 / 179), 60.33 \%(n=108 / 179), 8.93 \%(n=$ $16 / 179)$, and $5.11 \%(n=9 / 179)$, respectively (Figure 1 ,

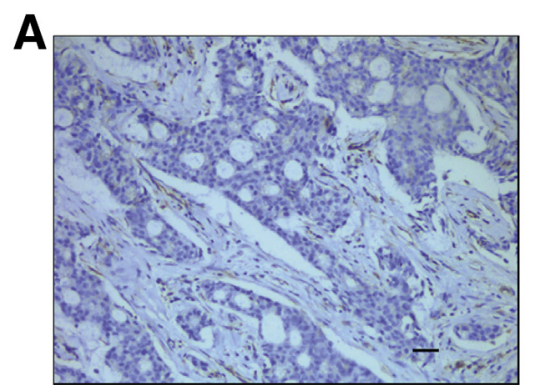

C

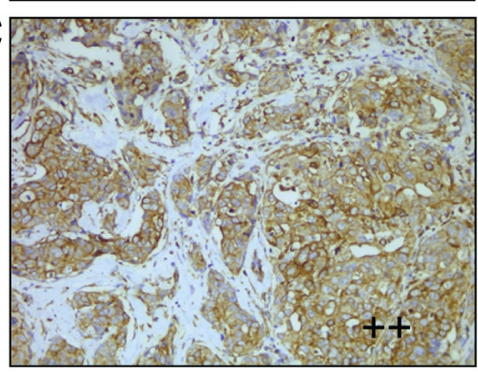

$\mathbf{E}$

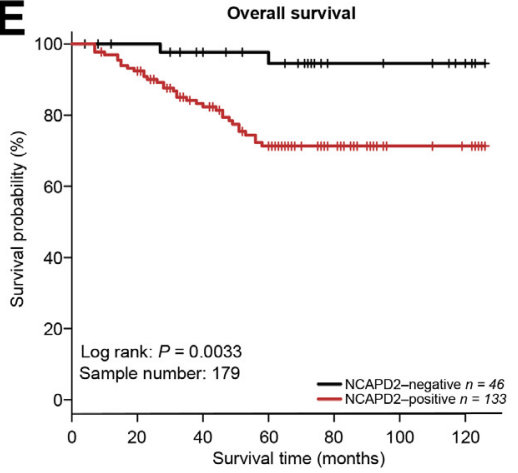

B

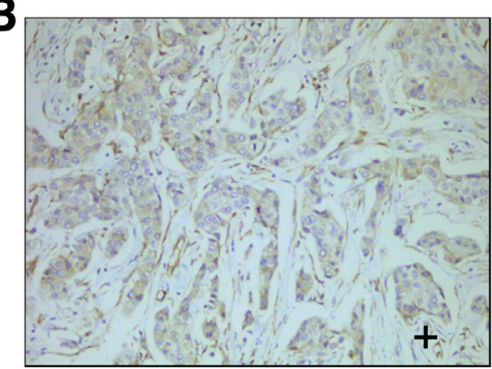

D

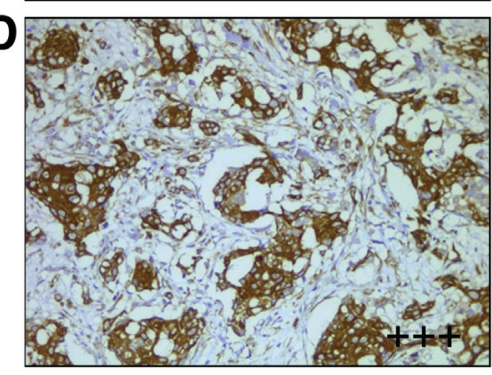

$\mathbf{F}$

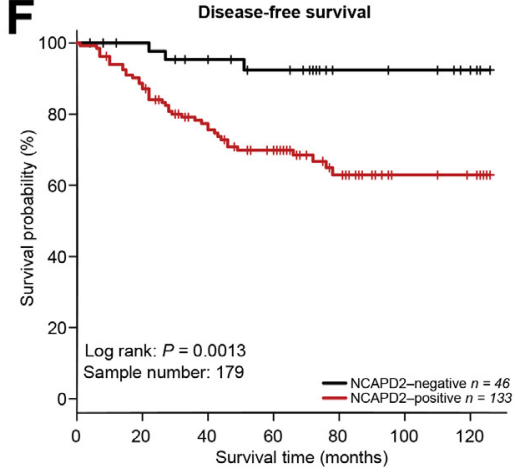

Figure 1 Non-SMC condensin I complex subunit D2 (NCAPD2) expression in triple-negative breast cancer (TNBC) tissues and the association between NCAPD2 expression and prognosis of patients with TNBC. A-D: Representative immunohistochemical staining results for NCAPD2 protein in TNBC tissues with negative $(\mathbf{A})$, mild positive (B), moderate positive (C), and marked positive (D) staining. $\mathbf{E}$ and $\mathrm{F}$ : A total of 179 patients with TNBC were divided into two groups based on NCAPD2 expression: negative staining represents the NCAPD2-negative group (black line), and mild, moderate, and marked positive staining represents the NCAPD2-positive group (red line). Positive NCAPD2 protein expression is a poor prognostic factor for overall (E) and disease-free (F) survival of patients with TNBC as indicated by Kaplan-Meier analysis. $n=46$ (E and F, NCAPD2-negative group); $n=133$ (E and $\mathbf{F}$, NCAPDS-positive group). Original magnification, $\times 200$ (A-D). - , negative staining; + , mild positive staining; ++ , moderate positive staining; +++ , marked positive staining. 
A-D). According to the staining intensity, the samples were divided into two groups, with negative staining defined as negative NCAPD2 expression group (NCAPD2 negative) and mild, moderate, and marked staining defined as positive NCAPD2 expression group (NCAPD2 positive). The correlations between NCAPD2 expression and a variety of clinical features were further analyzed. NCAPD2 expression was frequently associated with lymph node involvement $\left(P=3.84 \times 10^{-06}\right)$ (Table 1). However, the expression of NCAPD2 was not associated with patient age $(P=0.3042)$, tumor size $(P=0.2358)$, or pathologic grade $(P=0.3018)$.

Statistical analysis revealed that positive NCAPD2 expression was significantly correlated with poor overall survival (Figure 1E). A Cox proportional hazards model was applied to estimate the effect of NCAPD2 expression on overall survival. Both univariate and multivariate Cox regression analyses found that positive NCAPD2 expression increased the risk of TNBC-related death compared with negative NCAPD2 expression (Supplemental Table S1). Moreover, patients with positive NCAPD2 expression had significantly worse disease-free survival than those with negative expression (Figure 1F). Both univariate and multivariate Cox regression analyses found that positive NCAPD2 expression could increase the risk of TNBC progression (Supplemental Table S2). Taken together, these results indicate that NCAPD2 is an independent predictor of poor survival for patients with TNBC.

\section{NCAPD2 Participates in Multiple Aspects of Tumorigenesis in TNBC}

To determine the associations between NCAPD2 expression patterns and the biological features of cancer, the mRNA expression profiles of 99 TNBC tissue samples from TCGA program were analyzed. Pearson's product-moment correlation test was performed to identify genes that were significantly correlated with NCAPD2. Overall, 1728 genes were recognized to be closely correlated with NCAPD2 $(P<0.001$ and $\mid$ cor $\mid>0.3)$, including 956 positively correlated genes and 772 negatively correlated genes. Through GO enrichment analysis, it was found that these positively correlated genes were associated with cell proliferation (cell proliferation, cell division, cell cycle), RNA processing (mRNA processing, mRNA splicing, rRNA processing, mRNA and tRNA export from the nucleus), and DNA replication and repair (ontology: biological process) (Figure 2A). These positively correlated genes were mainly located in the nucleoplasm and cytoplasm (ontology: cellular component) (Figure 2C). On the contrary, the negatively correlated genes were associated with angiogenesis, cell migration, cell proliferation, and signal transduction (ontology: biological process) (Figure 2B) and mainly located in extracellular exosomes and extracellular space (ontology: cellular component) (Figure 2D). KEGG pathway analysis revealed that multiple cellular pathways, including DNA replication, cell cycle, spliceosome, RNA transport, complement and coagulation cascades, and lysosome, were significantly enriched (Figure 2, E and F). These data indicated that NCAPD2 participates in multiple aspects of TNBC tumorigenesis. Therefore, the differential expression of NCAPD2 may correspond to the different prognostic states of patients.

\section{NCAPD2 Knockdown Inhibits the Proliferation and Invasion of TNBC Cells}

The NCAPD2 mRNA expression of six normal and 99 tumor breast tissues from TCGA patients with TNBC was analyzed. The mRNA expression of NCAPD2 in TNBC tissues was significantly higher than in the normal breast tissues that from patients with TNBC (Supplemental Figure S1). To further investigate the biological roles of NCAPD2 in TNBC tumorigenesis and to uncover the veil of the reason why NCAPD2 differential expression caused different prognostic states of patients with TNBC, TNBC cell models were constructed in which NCAPD2 was knocked down. NCAPD2 expression levels were first examined in the three human TNBC cell lines MDA-MB231, MDA-MB-468, and MDA-MB-453. The results indicate that the expression levels of NCAPD2 were varied in

Table 1 Association between Non-SMC Condensin I Complex Subunit D2 (NCAPD2) Expression and the Clinicopathologic Characteristics of 179 Patients with TNBC

\begin{tabular}{|c|c|c|c|}
\hline Characteristic & $\begin{array}{l}\text { NCAPD2 } \\
\text { negative, } \\
n(\text { total }=46)\end{array}$ & $\begin{array}{l}\text { NCAPD2 } \\
\text { positive, } \\
n(\text { total }=133)\end{array}$ & $P$ \\
\hline $\begin{array}{l}\text { Age, years } \\
\text { (median } \\
=52 \text { years) }\end{array}$ & & & 0.3042 \\
\hline$\leq 52$ & 23 & 80 & \\
\hline$>52$ & 23 & 53 & \\
\hline Tumor size & & & 0.2358 \\
\hline $\mathrm{T} 1$ & 6 & 17 & \\
\hline $\mathrm{T} 2$ & 34 & 82 & \\
\hline T3/T4 & 4 & 25 & \\
\hline Pathologic grade & & & 0.3018 \\
\hline 1 & 0 & 5 & \\
\hline 2 & 21 & 70 & \\
\hline 3 & 18 & 44 & \\
\hline $\begin{array}{l}\text { Lymph node } \\
\quad \text { involvement }\end{array}$ & & & $3.84 \times 10^{-06}$ \\
\hline No & 36 & 43 & \\
\hline N1 & 6 & 47 & \\
\hline $\mathrm{N} 2$ & 4 & 28 & \\
\hline N3 & 0 & 10 & \\
\hline
\end{tabular}

Two cases in the NCAPD2-negative group and nine cases in NCAPD2positive group have missing tumor size characteristics. Seven cases in the NCAPD2-negative group and 14 cases in NCAPD2-positive group have missing pathologic grade characteristics. Five cases in the NCAPD2-positive group have missing lymph node involvement characteristics. 
these three TNBC cell lines and that the expression levels were consistent at the RNA and protein levels (Supplemental Figure S2, A and C).

TNBC cells were transfected with either siNCAPD2 or $\mathrm{NC}$ to deplete NCAPD2. The efficiency of siRNA-mediated knockdown of NCAPD2 was validated by real-time PCR and Western blotting. TNBC cells transfected with siNCAPD2 showed a noteworthy decrease in the NCAPD2 mRNA and protein expression levels compared with the NC group (Supplemental Figure S2, B and D). The effect of siRNAs on cell proliferation was evaluated by CCK-8 assays. The results indicate that the proliferation of TNBC cells was significantly inhibited at 96 and 120 hours after NCAPD2 knockdown compared with that of the NC group (Figure 3A). Moreover, Transwell assays revealed that down-regulation of NCAPD2 resulted in a significant decrease in the invasive capabilities of TNBC cells (Figure 3B), which fits better with the finding that low expression of NCAPD2 is associated with less lymph node metastasis and better overall survival.
NCAPD2 Knockdown Induces $\mathrm{G}_{2} / \mathrm{M}$ Arrest in TNBC Cells, which Generates Polyploid Cells and Enhances Apoptosis

To address how NCAPD2 contributes to cell proliferation, the cell cycle of TNBC cells was analyzed by flow cytometry after siNCAPD2 or NC transfection. Down-regulation of NCAPD2 caused an accumulation of cells in $\mathrm{G}_{2} / \mathrm{M}$ phase compared with the NC group of TNBC cells (Figure 4A). In addition, a significant increase of polyploid cells was observed after NCAPD2 depletion (Figure 4B).

Furthermore, the rate of cell apoptosis was studied after NCAPD2 knockdown. TNBC cells were stained with Annexin V-FITC/PI after transfection with siNCAPD2 or $\mathrm{NC}$ and then analyzed by flow cytometry. An increased fraction of apoptotic cells after NCAPD2 knockdown was found compared with the NC group (Figure 5). These results indicate that the growth-inhibitory effect of NCAPD2 depletion on TNBC cells was attributed to $G_{2} / M$ arrest during the cell cycle, polyploid cell formation, and cell apoptosis.
A
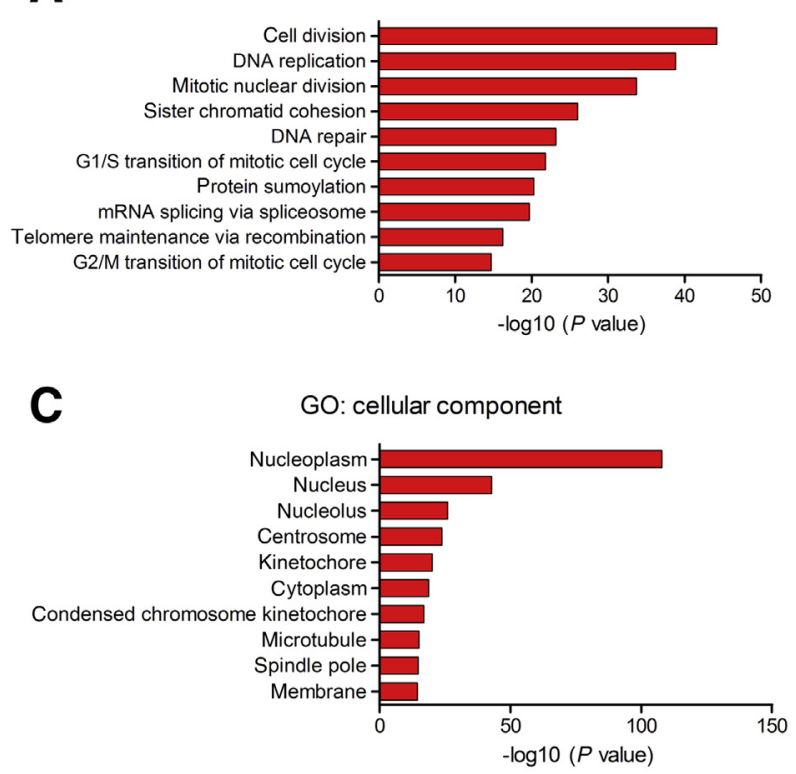

E

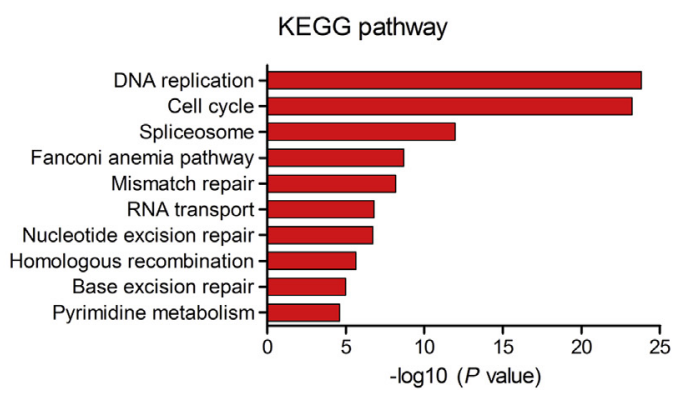

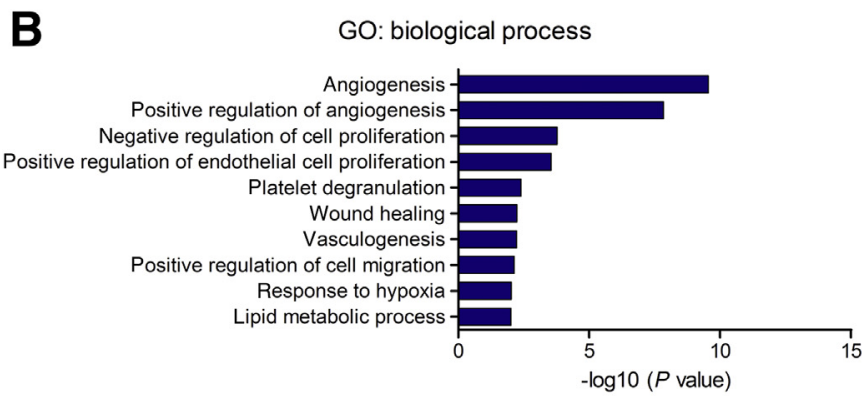

D
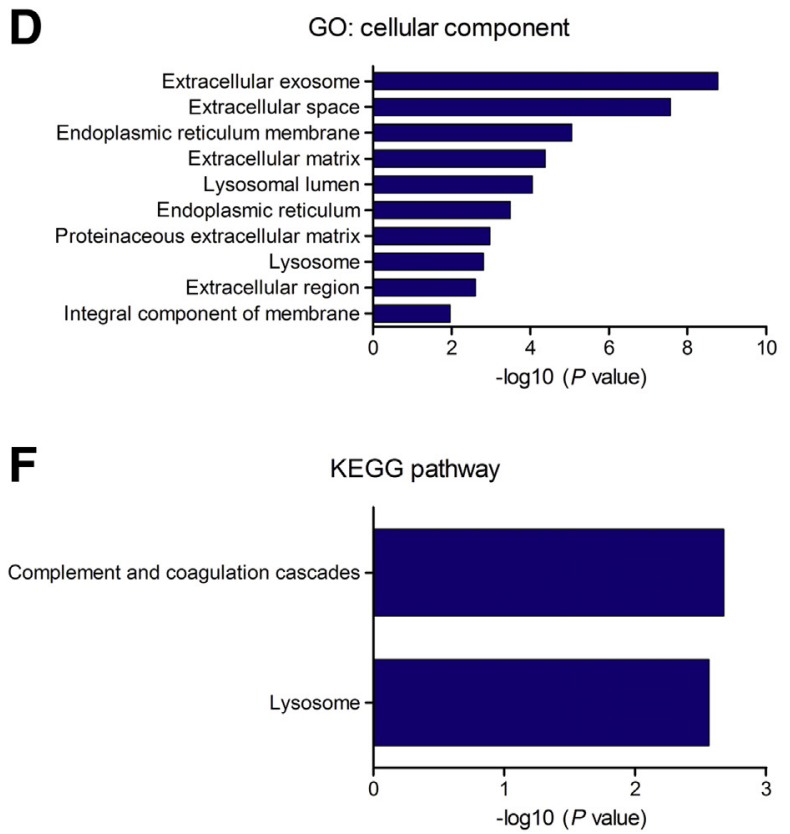

Figure 2 Non-SMC condensin I complex subunit D2 (NCAPD2) participates in multiple aspects of triple-negative breast cancer tumorigenesis. Representative Gene Ontology (GO) biological process (A), G0 cellular component (C), and KEGG pathway terms (E) for genes positively correlated with NCAPD2 expression. Representative GO biological process (B), G0 cellular component (D), and KEGG pathway terms (F) for genes negatively correlated with NCAPD2 expression. 


\section{NCAPD2 Participates in p53 Signaling Pathway}

To further explore mechanisms by which NCAPD2 applied to execute biological functions, a protein-protein interaction network was constructed using NCAPD2 and the 1728 aforementioned correlated genes. The positively correlated genes constituted a network with 909 nodes and 23,436 links (positive network), and negatively correlated genes constituted a network with 652 nodes and 2282 links (negative network) (Supplemental Figure S3). Intriguingly, the negative network did not contain NCAPD2, suggesting that these negatively correlated genes might have a low influence on the biological function implementing of NCAPD2. Afterward, MCODE was applied to identify highly interconnected clusters in the positive network and in the network constructed by all 1729 genes, and the cluster with the highest score was chosen from each network. Surprisingly, the two selected clusters were totally identical and included NCAPD2 (Figure 6A), which further verified the negatively correlated genes might not interact with NCAPD2. Cluster 1 consisted of 134 nodes that all were positively correlated genes and 7536 links. GO analysis
A

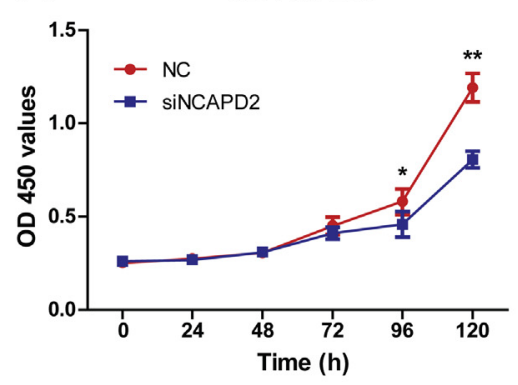

B

MDA-MB-231
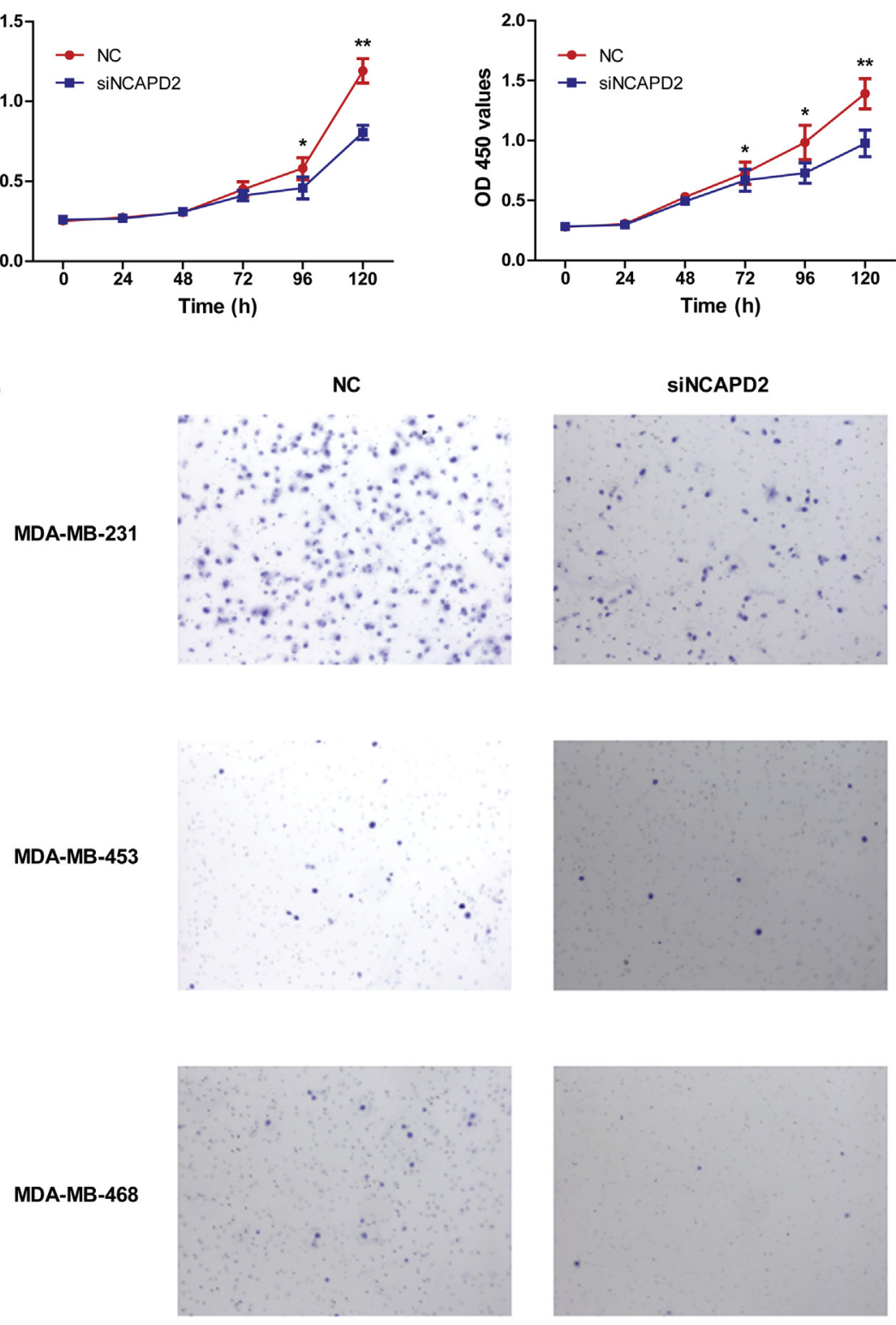

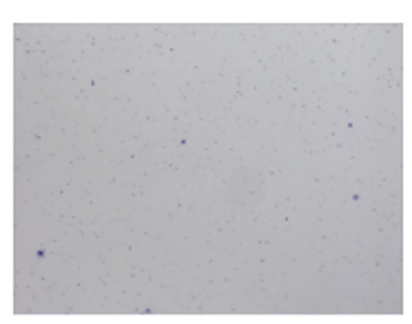

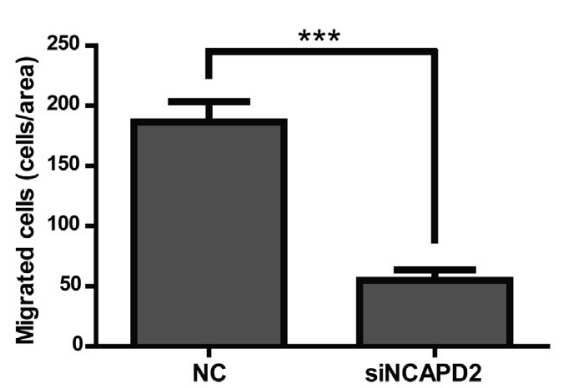

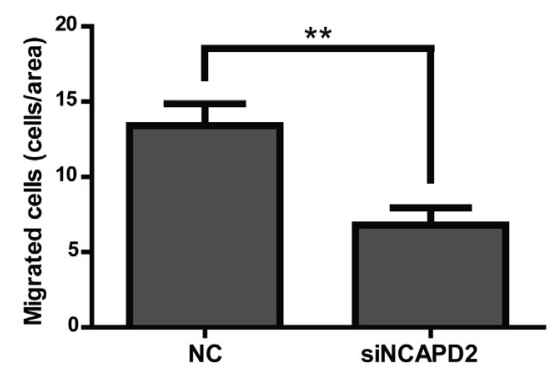

MDA-MB-468
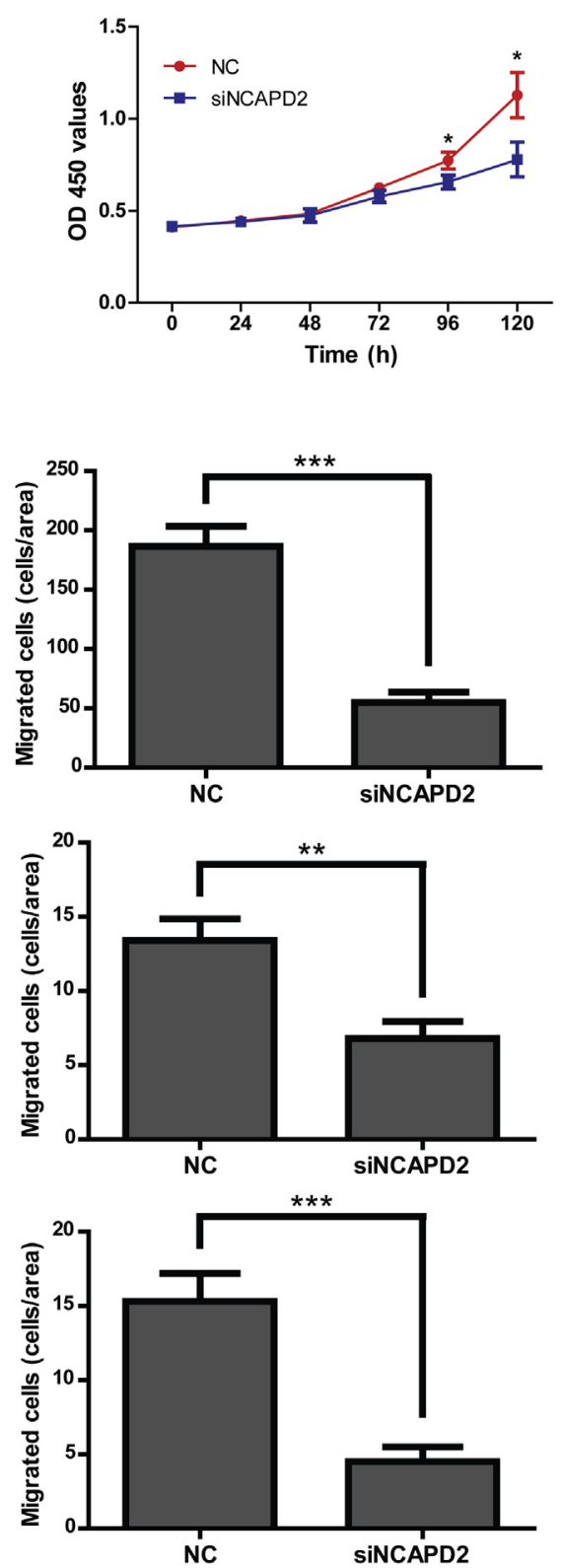

Figure 3 Down-regulation of non-SMC condensin I complex subunit D2 (NCAPD2) inhibits the proliferation and invasion of triple-negative breast cancer (TNBC) cells. A: Cell Counting Kit 8 assays were used to evaluate the proliferation of TNBC cells after transfection with siRNA targeting NCAPD2 (siNCAPD2) or nontargeting control (NC). B: Transwell invasion assays of TNBC cells 48 hours after transfection with siNCAPD2 or NC. Data are expressed as means \pm SEM. $n=3$ independent experiments. ${ }^{*} P<0.05,{ }^{* *} P<0.01$, and ${ }^{* * *} P<0.001$ versus siNCAPD2. Original magnification, $\times 200$. 
found that the 134 nodes were enriched in many aspects of cell cycle, and KEGG enrichment found that the 134 nodes were significantly enriched in p53 signaling pathway and other pathways (Figure 6, B and C).

Eight of the 134 genes of cluster 1 were enriched in p53 signaling pathway, including $C C N B 1, C C N B 2, C C N E 2$, $C D K 1, C D K 2, C H E K 1, G T S E 1$, and RRM2. Thereinto, $C C N B 1, C C N B 2$, and $C D K 1$ play crucial roles in $\mathrm{G}_{2} / \mathrm{M}$ transition phase of the cell cycle, which was consistent with our knockdown result that down-regulation of NCAPD2 caused an accumulation of TNBC cells in $\mathrm{G}_{2} / \mathrm{M}$ phase. $C C N E 2, C D K 1$, and $C D K 2$ play roles in cell cycle $\mathrm{G}_{1} / \mathrm{S}$ transition. $C H E K 1$ is required for checkpoint-mediated cell cycle arrest, and GTSE1, expressed only in the $\mathrm{S}$ and $\mathrm{G}_{2}$ phases of the cell cycle, participates in the DNA damage-induced apoptosis, which was consistent with the result that knockdown of $N C A P D 2$ enhanced apoptosis. All the above results indicate that NCAPD2 might participate in p53 signaling pathway to execute cell cycle-related biological functions.

\section{Discussion}

TNBC accounts for $15 \%$ to $20 \%$ of all breast cancers; however, it causes a disproportionate percentage of breast cancer-related deaths. The aggressive phenotype, the high molecular heterogeneity, and the absence of targeted therapies of TNBC make it intractable. Patients with TNBC have a high risk of both local and distant recurrence and metastases,
A
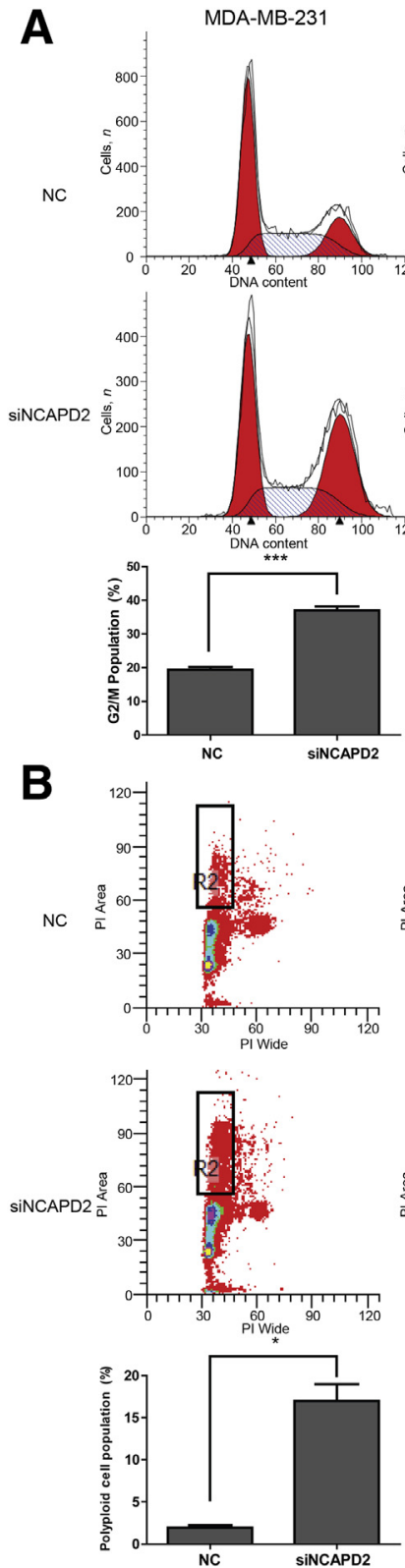
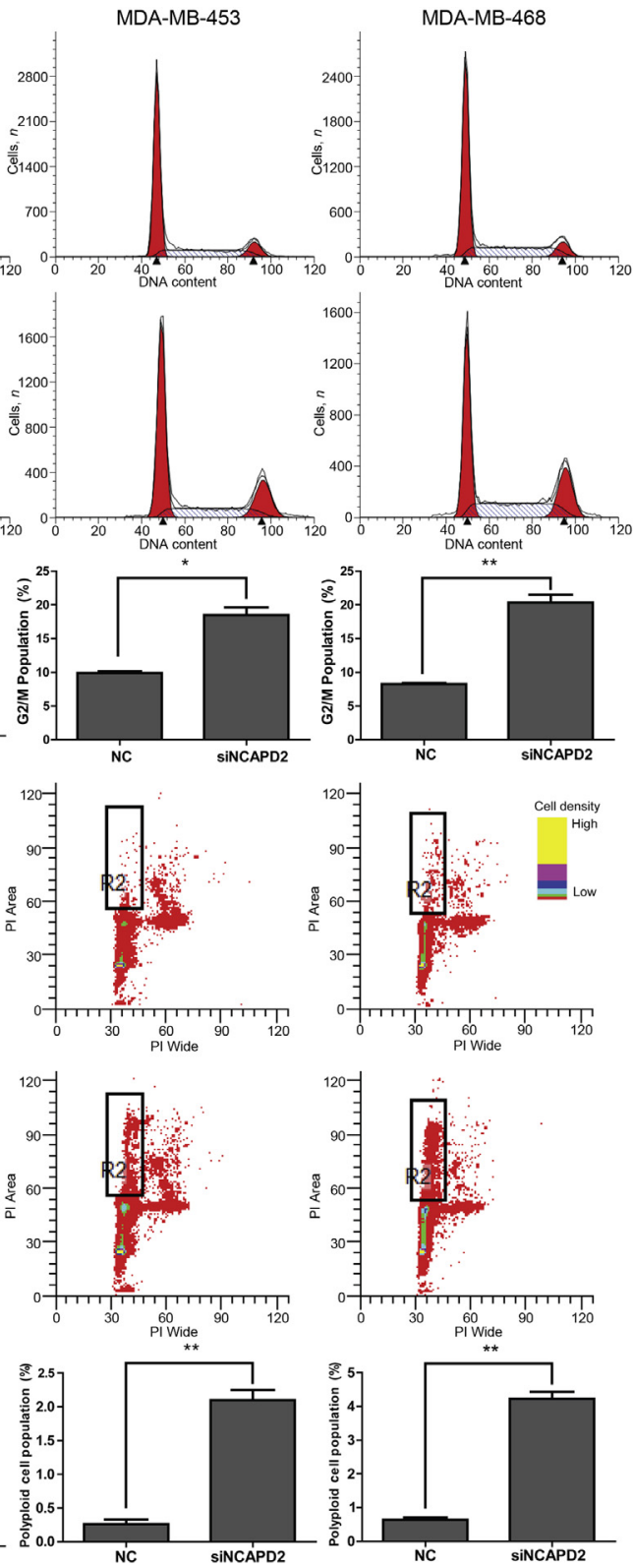

Figure 4 Down-regulation of non-SMC condensin I complex subunit D2 (NCAPD2) induces $G_{2} / M$ phase blockage and polyploid cell formation in triple-negative breast cancer (TNBC) cells. TNBC cells were transfected with siRNA targeting NCAPD2 (siNCAPD2) or nontargeting control (NC). Then 96 hours after transfection, the fixed and permeabilized cells were stained for DNA content with propidium iodide (PI) and analyzed by flow cytometry to detect the cell cycle (A) and the polyploid cells (B). The dot within the black frame in $\mathbf{B}$ represents polyploid cells that have the same PI width value as normal cells but a higher PI area value. Data are expressed as means \pm SEM. $n=3$ independent experiments. ${ }^{*} P<0.05,{ }^{* *} P<0.01$, and ${ }^{* * *} P<0.001$. 
which lead to a poor prognosis. ${ }^{26,27}$ Therefore, it is necessary to elucidate the molecular mechanisms and to identify potential therapeutic targets for TNBC. The expression level of NCAPD2 is constant during the cell cycle, but its localization changes with different cell cycle phases. From mitotic interphase to early prophase, most NCAPD2 is soluble in the cytoplasm, whereas small amounts are associated with insoluble nuclear components. After breakdown of the nuclear envelope, NCAPD2 climbs up on the chromosome arms in late prophase and is not separated from the chromosome until the end of M phase. NCAPD2 is important for the assembly and segregation of mitotic chromosomes, which is consistent with its localization during the cell cycle. ${ }^{13,15,21}$ Recently, a study found that polymorphisms of NCAPD2 are associated with Parkinson disease. ${ }^{28}$ Nonetheless, no study has linked this gene to cancer. In our study, we found a close association between NCAPD2 and cancer for the first time. All four subtypes of breast cancer, including the luminal subtype (ER and/or PR positive, HER2 negative), HER2 subtype, luminal (HER2 positive and ER and/or PR positive), HER2 subtype, nonluminal (HER2 positive and ER and PR negative), and basal-like subtype (HER2 negative and ER and PR negative; TNBC), contain NCAPD2-positive and NCAPD2-negative protein expression cases. The rates of NCAPD2-positive expression cases in luminal, HER2 subtype luminal, HER2 subtype nonluminal, and basal-like (TNBC, reported in our article) subtypes were $32.99 \%(n=64 / 194), 39.39 \%(n=13 / 33), 44.12 \%(n=$ $15 / 34)$, and $74.30 \%(n=133 / 179)$, respectively. In patients with TNBC, NCAPD2 was an independent predictor of prognosis. Positive NCAPD2 protein expression was significantly correlated with poor overall survival and
MDA-MB-231
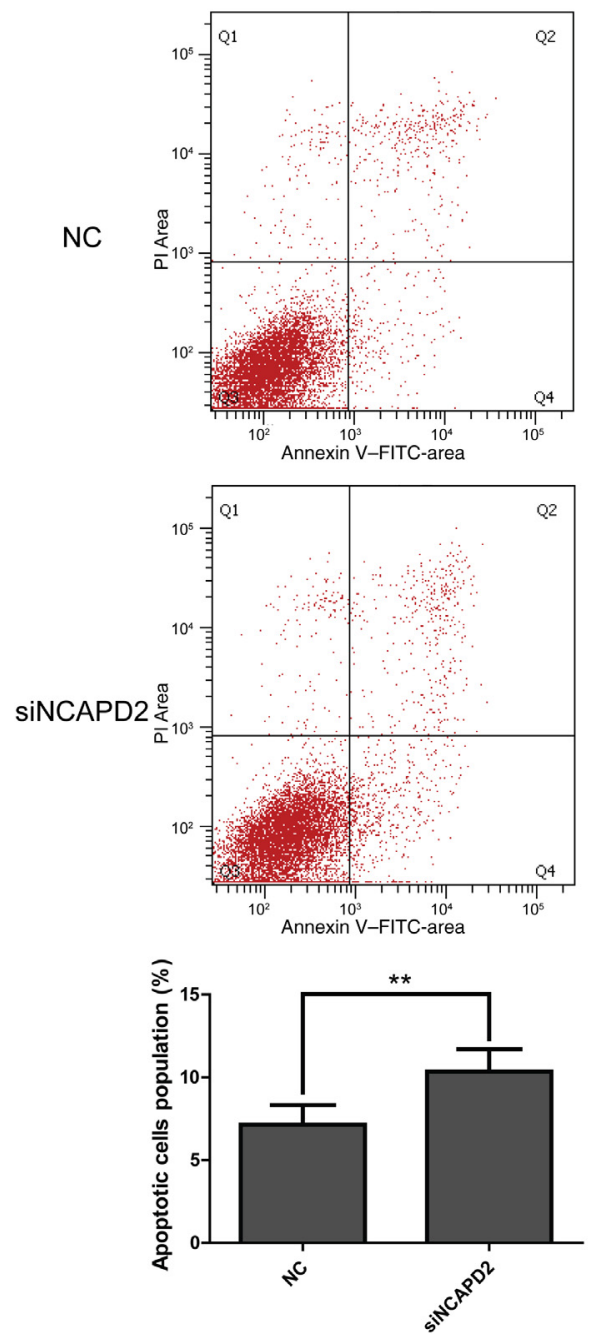

MDA-MB-453
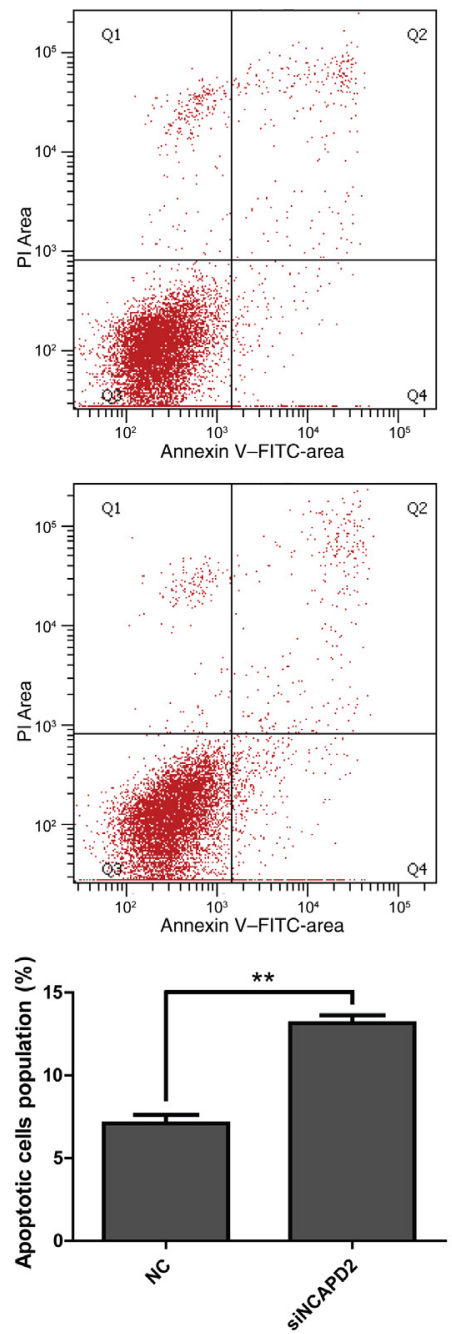

MDA-MB-468
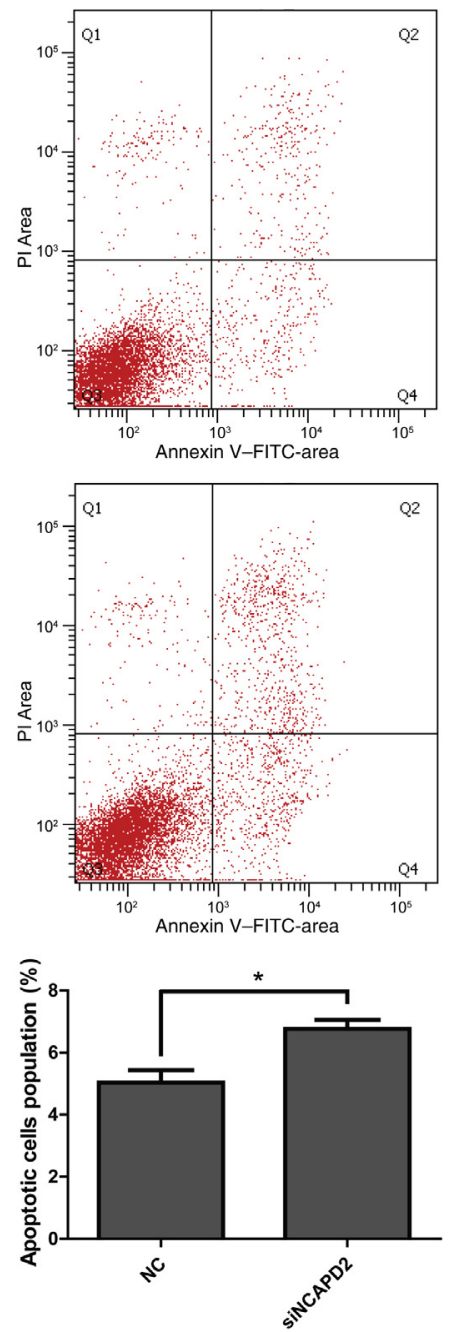

Figure 5 Down-regulation of non-SMC condensin I complex subunit D2 (NCAPD2) induces cell apoptosis in triple-negative breast cancer (TNBC) cells. TNBC cells were transfected with siRNA targeting NCAPD2 (siNCAPD2) or nontargeting control (NC). Then 96 hours after transfection, cells were stained with Annexin V-fluorescein isothiocyanate (FITC) and propidium iodide (PI) and then analyzed by flow cytometry. Box Q3 points represent living cells; box Q1 points, dead cells caused by mechanical damage; and box $Q 2$ and 04 points, apoptotic cells. Data are expressed as means \pm SEM. $n=3$ independent experiments. ${ }^{*} P<0.05,{ }^{* *} P<0.01$. 
worse disease-free survival of patients with TNMB. In addition, the risk of TNBC-related death in the NCAPD2positive group was nearly fivefold greater than that in the NCAPD2-negative group.

In this study, the correlation analysis of the mRNA expression data of 99 TNBC samples from TCGA found that NCAPD2 was associated with the cell cycle, cell proliferation, cell division, and cell migration, which was further validated by NCAPD2 low-expression cell models. In MDA-MB-231, MDA-MB-468, and MDA-MB-453 TNBC cells, the proportion of cells in $G_{2} / M$ phase changed significantly after NCAPD2 depletion. Compared with the $\mathrm{NC}$ group, the cell proportion of $\mathrm{G}_{2} / \mathrm{M}$ phase was increased twofold to threefold in the siNCAPD2 group,

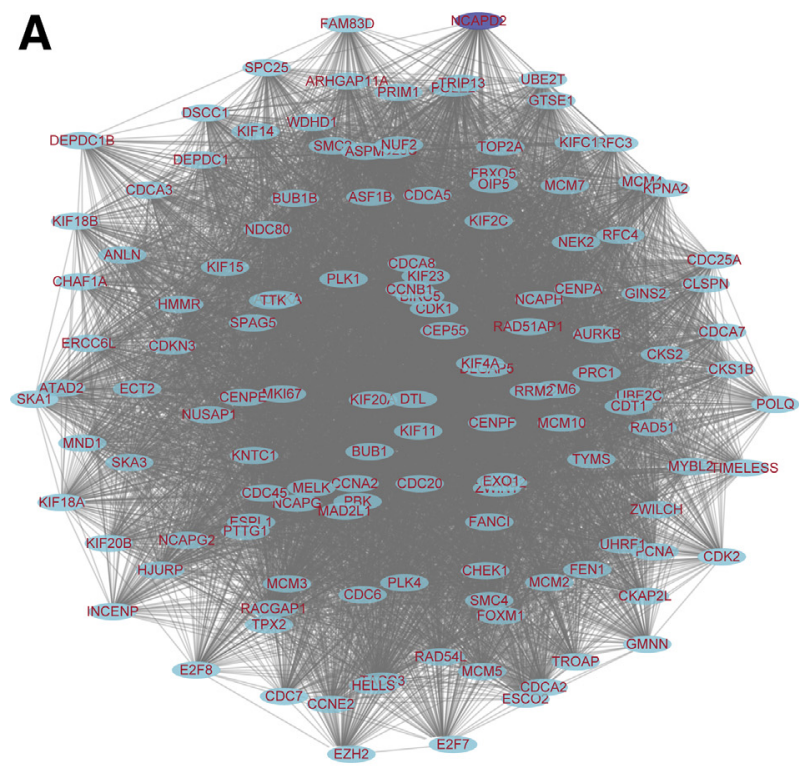

B

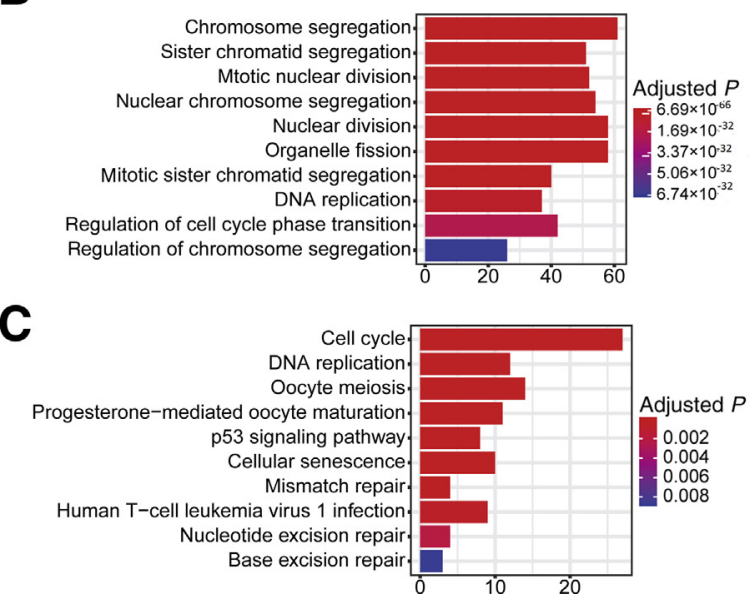

Figure 6 MCODE cluster from non-SMC condensin I complex subunit D2 (NCAPD2) protein-protein interaction (PPI) network and functional enrichment of cluster genes. A: MCODE cluster 1 with an MCODE score of 113.323 from NCAPD2 PPI network includes 134 nodes and 7536 links. NCAPD2 is involved in the cluster 1. B and C: Representative Gene Ontology (G0) biological process (B) and KEGG pathway terms (C) of the 134 nodes in cluster 1. which was consistent with the previous report that NCAPD2 depletion caused an abnormal accumulation of cells in prometaphase. $^{13}$ Moreover, the $\mathrm{G}_{2} / \mathrm{M}$ block caused by NCAPD2 down-regulation could significantly suppress the proliferation of TNBC cells and lead to the failure of complete mitosis in some cells. For cells that were unable to successfully complete mitosis, they either quit the process of mitosis and became polyploid cells or underwent programed cell death, which might be realized through p53 signaling pathway. The down-regulation of NCAPD2 suppressed invasiveness of TNBC cells, which may be attributable to the ability of NCPAD2 to stabilize the centrosome and promote microtubule formation. ${ }^{23,24}$ In addition, low expression of NCAPD2 was associated with less lymph node metastasis. Hence, the expression of NCAPD2 might be related with epithelial to mesenchymal transition (EMT). Twenty-three genes that significantly co-expressed with NCAPD2 (FAM83D, HDAC2, TRIM28, EZH2, NOLC1, STRAP, BMP5, LRP6, TGFB1I1, MSX1, DACT3, PDCD4, $H G F, M S X 2, A C V R L 1, T G F B R 2, E N G, D A B 2, B M P 4$, EPHA3, SPRY1, TGFB3, SNAI2) in the 136-gene set related to EMT (downloaded from GO: 0001837, EMT) were found by analyzing 99 TNBC mRNA expression data from TCGA. SNAI2 (alias SNAIL2 or SLUG) is an important transcription factor that can induce EMT. The SNAI2induced EMT is partially attributable to the direct repression of E-cadherin expression. ${ }^{29}$ Many signaling molecules can induce $S N A I 2$ gene expression, including $B M P 5, H G F$, $B M P 4$, and TGFB3, which appear in our data. ${ }^{30} F A M 83 D$ was reported as an oncogene, and overexpression of FAM $83 D$ was reported to induce EMT in breast cancer cells through the mTOR signaling pathway. ${ }^{31}$ Although the pivotal role of NCAPD2 in TNBC progression was found in this study, the underlying specific molecular mechanisms and the potential use of NCAPD2 as a prognostic marker in TNBC require further investigation.

In conclusion, for the first time, we report the close association between NCAPD2 and TNBC. We found that NCPAD2 played an important role in the cell cycle and migration of TNBC cell lines and potentially participated in p53 signaling pathway. Positive NCAPD2 expression was frequently associated with lymph node involvement. Importantly, our results indicate that NCAPD2 expression was significantly correlated with the overall survival and disease-free survival of patients with TNBC and acted as an independent poor prognostic factor.

\section{Author Contributions}

S.C. and L.F. conceived and designed the project; F.L., Z.Y., C.Z., and M.K. performed the experiments and analyzed the data; Y.Z., C.Z., and M.K. wrote the manuscript; F.L., M.R., and X.D. collected the clinical samples and conducted the follow-up; T.X. and L.F. revised the manuscript. 


\section{Supplemental Data}

Supplemental material for this article can be found at http://doi.org/10.1016/j.ajpath.2019.09.014.

\section{References}

1. Carey LA, Dees EC, Sawyer L, Gatti L, Moore DT, Collichio F, Ollila DW, Sartor CI, Graham ML, Perou CM: The triple negative paradox: primary tumor chemosensitivity of breast cancer subtypes. Clin Cancer Res 2007, 13:2329-2334

2. Carey LA, Perou CM, Livasy CA, Dressler LG, Cowan D, Conway K, Karaca G, Troester MA, Tse CK, Edmiston S, Deming SL, Geradts J, Cheang MC, Nielsen TO, Moorman PG, Earp HS, Millikan RC: Race, breast cancer subtypes, and survival in the Carolina Breast Cancer Study. JAMA 2006, 295:2492-2502

3. Sorlie T, Perou CM, Tibshirani R, Aas T, Geisler S, Johnsen H, Hastie T, Eisen MB, van de Rijn M, Jeffrey SS, Thorsen T, Quist H, Matese JC, Brown PO, Botstein D, Lonning PE, Borresen-Dale AL: Gene expression patterns of breast carcinomas distinguish tumor subclasses with clinical implications. Proc Natl Acad Sci U S A 2001, 98:10869-10874

4. Sorlie T, Tibshirani R, Parker J, Hastie T, Marron JS, Nobel A, Deng S, Johnsen H, Pesich R, Geisler S, Demeter J, Perou CM, Lonning PE, Brown PO, Borresen-Dale AL, Botstein D: Repeated observation of breast tumor subtypes in independent gene expression data sets. Proc Natl Acad Sci U S A 2003, 100:8418-8423

5. Bauer KR, Brown M, Cress RD, Parise CA, Caggiano V: Descriptive analysis of estrogen receptor (ER)-negative, progesterone receptor (PR)-negative, and HER2-negative invasive breast cancer, the socalled triple-negative phenotype: a population-based study from the California Cancer Registry. Cancer 2007, 109:1721-1728

6. Kennecke H, Yerushalmi R, Woods R, Cheang MC, Voduc D, Speers CH, Nielsen TO, Gelmon K: Metastatic behavior of breast cancer subtypes. J Clin Oncol 2010, 28:3271-3277

7. Dent R, Trudeau M, Pritchard KI, Hanna WM, Kahn HK, Sawka CA, Lickley LA, Rawlinson E, Sun P, Narod SA: Triple-negative breast cancer: clinical features and patterns of recurrence. Clin Cancer Res 2007, 13:4429-4434

8. Abramson VG, Lehmann BD, Ballinger TJ, Pietenpol JA: Subtyping of triple-negative breast cancer: implications for therapy. Cancer 2015, 121:8-16

9. Perou CM, Sorlie T, Eisen MB, van de Rijn M, Jeffrey SS, Rees CA, Pollack JR, Ross DT, Johnsen H, Akslen LA, Fluge O, Pergamenschikov A, Williams C, Zhu SX, Lonning PE, Borresen-Dale AL, Brown PO, Botstein D: Molecular portraits of human breast tumours. Nature 2000, 406:747-752

10. Mustacchi G, De Laurentiis M: The role of taxanes in triple-negative breast cancer: literature review. Drug Des Devel Ther 2015, 9: 4303-4318

11. Hirano T: Chromosome cohesion, condensation, and separation. Annu Rev Biochem 2000, 69:115-144

12. Swedlow JR, Hirano T: The making of the mitotic chromosome: modern insights into classical questions. Mol Cell 2003, 11:557-569

13. Watrin E, Legagneux V: Contribution of hCAP-D2, a non-SMC subunit of condensin I, to chromosome and chromosomal protein dynamics during mitosis. Mol Cell Biol 2005, 25:740-750

14. Verlinden L, Eelen G, Beullens I, Van Camp M, Van Hummelen P, Engelen K, Van Hellemont R, Marchal K, De Moor B, Foijer F, Te Riele H, Beullens M, Bollen M, Mathieu C, Bouillon R, Verstuyf A: Characterization of the condensin component Cnap1 and protein kinase Melk as novel E2F target genes down-regulated by 1,25dihydroxyvitamin D3. J Biol Chem 2005, 280:37319-37330

15. Ball AR Jr, Schmiesing JA, Zhou C, Gregson HC, Okada Y, Doi T, Yokomori K: Identification of a chromosome-targeting domain in the human condensin subunit CNAP1/hCAP-D2/Eg7. Mol Cell Biol 2002, 22:5769-5781

16. Neuwald AF, Hirano T: HEAT repeats associated with condensins, cohesins, and other complexes involved in chromosome-related functions. Genome Res 2000, 10:1445-1452

17. Groves MR, Barford D: Topological characteristics of helical repeat proteins. Curr Opin Struct Biol 1999, 9:383-389

18. Conroy PC, Saladino C, Dantas TJ, Lalor P, Dockery P, Morrison CG: C-NAP1 and rootletin restrain DNA damage-induced centriole splitting and facilitate ciliogenesis. Cell Cycle 2012, 11:3769-3778

19. Fang G, Zhang D, Yin H, Zheng L, Bi X, Yuan L: Centlein mediates an interaction between C-Nap1 and Cep68 to maintain centrosome cohesion. J Cell Sci 2014, 127:1631-1639

20. Martin CA, Murray JE, Carroll P, Leitch A, Mackenzie KJ, Halachev M, Fetit AE, Keith C, Bicknell LS, Fluteau A, Gautier P, Hall EA, Joss S, Soares G, Silva J, Bober MB, Duker A, Wise CA, Quigley AJ, Phadke SR: Deciphering Developmental Disorders Study; Wood AJ, Vagnarelli P, Jackson AP: Mutations in genes encoding condensin complex proteins cause microcephaly through decatenation failure at mitosis. Genes Dev 2016, 30:2158-2172

21. Schmiesing JA, Gregson HC, Zhou S, Yokomori K: A human condensin complex containing hCAP-C-hCAP-E and CNAP1, a homolog of Xenopus XCAP-D2, colocalizes with phosphorylated histone H3 during the early stage of mitotic chromosome condensation. Mol Cell Biol 2000, 20:6996-7006

22. Ono T, Fang Y, Spector DL, Hirano T: Spatial and temporal regulation of Condensins I and II in mitotic chromosome assembly in human cells. Mol Biol Cell 2004, 15:3296-3308

23. Yang J, Adamian M, Li T: Rootletin interacts with C-Nap1 and may function as a physical linker between the pair of centrioles/basal bodies in cells. Mol Biol Cell 2006, 17:1033-1040

24. Conroy PC, Saladino C, Dantas TJ, Lalor P, Dockery P, Morrison CG C-NAP1 and rootletin restrain DNA damage-induced centriole splitting and facilitate ciliogenesis. Cell Cycle 2012, 11:3769-3778

25. Tsai CY, Wang CS, Tsai MM, Chi HC, Cheng WL, Tseng YH, Chen CY, Lin CD, Wu JI, Wang LH, Lin KH: Interleukin-32 increases human gastric cancer cell invasion associated with tumor progression and metastasis. Clin Cancer Res 2014, 20:2276-2288

26. Agarwal G, Nanda G, Lal P, Mishra A, Agarwal A, Agrawal V, Krishnani N: Outcomes of triple-negative breast cancers (TNBC) compared with non-TNBC: does the survival vary for all stages? World J Surg 2016, 40:1362-1372

27. Jiao Q, Wu A, Shao G, Peng H, Wang M, Ji S, Liu P, Zhang J: The latest progress in research on triple negative breast cancer (TNBC): risk factors, possible therapeutic targets and prognostic markers. J Thorac Dis 2014, 6:1329-1335

28. Zhang P, Liu L, Huang J, Shao L, Wang H, Xiong N, Wang T: NonSMC condensin I complex, subunit D2 gene polymorphisms are associated with Parkinson's disease: a Han Chinese study. Genome 2014, 57:253-257

29. Zeisberg M, Neilson EG: Biomarkers for epithelial-mesenchymal transitions. J Clin Invest 2009, 119:1429-1437

30. Barrallo-Gimeno A, Nieto MA: The Snail genes as inducers of cell movement and survival: implications in development and cancer. Development 2005, 132:3151-3161

31. Wang Z, Liu Y, Zhang P, Zhang W, Wang W, Curr K, Wei G, Mao JH: FAM83D promotes cell proliferation and motility by downregulating tumor suppressor gene FBXW7. Oncotarget 2013, 4: $2476-2486$ 